\title{
Performing Non-sexism via Degendering Phoric Forms in English: The Gap between Rules and Practice as Observed in the 9th Edition of Oxford Advanced Learner's Dictionary of Current English
}

Nshindi-Germain Mulamba, Department of English Letters and Civilization, University of Lubumbashi, DR Congo (mulambagermain56@gmail.com) and

Francis Ngoyi Crequi Tshimanga, Department of English and African Culture, Teacher Training College of Mbujimayi, DR Congo (ftshimangangoyi@gmail.com)

\begin{abstract}
Non-sexism is one of the outstanding and obvious proofs of how social and cultural changes are taken into account in the English language. However, it is still a usage problem for natives and learners alike. This paper uses the degendering of phoric elements as an illustration of efforts in the 9th edition of Oxford Advanced Learner's Dictionary of Current English (OALD9) to capture and express social and cultural changes in the English language. It also attempts to point out some mismatches between rules and actual practice in this enterprise. Finally, it intends to show how the dictionary may act as an ideological tool, imposing, sustaining, highlighting, and perpetuating some points of view to the detriment of others. In practice, the use of more than one structure to achieve non-sexism makes fluency difficult and writing cumbersome.
\end{abstract}

Keywords: GENDER, PHORIC ELEMENTS, SEXISM, NON-SEXISM, DICTIONARY, IDEOLOGY, USAGE PROBLEM

Résumé: La pratique du non-sexisme à travers la neutralisation du genre des anaphores en anglais: L'écart entre les règles et la pratique tel que perçu dans la neuvième édition d'Oxford Advanced Learner's Dictionary of Current English. L'emploi du langage non sexiste en anglais est une preuve patente de la prise en compte par la langue des mutations sociales et culturelles. Cependant celui-ci demeure un problème d'usage tant pour les locuteurs natifs que pour les apprenants. Cet article puise dans la neutralisation du genre des anaphores comme un exemple des efforts déployés par la neuvième édition d'Oxford Advanced Learner's Dictionary of Current English (OALD9) afin de cerner et exprimer lesdits changements dans 
la langue anglaise. Cet article essaie également d'identifier les points de convergence et/ou de divergence entre les règles établies et la pratique réelle dans la neutralisation du genre structurelle de la langue anglaise. En définitive, il envisage démontrer comment le dictionnaire peut servir d'outil idéologique, imposant, soutenant, mettant en exergue, et perpétuant certains points de vue au détriment d'autres. En pratique, l'emploi multiple des structures pour réaliser le non-sexisme rend difficile la fluidité du langage et l'écriture encombrante.

Mots clés: GENRE, ANAPHORES, SEXISME, NON-SEXISME, DICTIONNAIRE, IDEOLOGIE, PROBLEME D'USAGE

\section{Introduction}

For decades, gender-referring usage in English has tended to become an issue not only in English teaching but even in English native speakers' everyday communication (Mulamba and Tshimanga 2006). Language users have been confronted with the rise of new grammatical, lexical and discourse rules which compel them to become more and more aware of how they use language. That is, far from remaining purely descriptive, some grammars and studies have tended towards 'prescriptivism' to impose the new rules. The latter serve, among other things, to account for the changes in the language usage as a result of cultural and social changes, viz. gender.

To state it differently, these new rules challenge the traditional ones (e.g. the generic masculine) to such an extent that language use has become less and less intuitive even for native speakers. At times, speakers have to stop and think about the appropriate form to use in order not to commit a social blunder. The case in question herein is that of sexist language and how to avoid it. The present paper thus aims at addressing sexism through the treatment of degendering phoric forms in English in the Oxford Advanced Learner's Dictionary of Current English, 9th edition (OALD9 henceforth). By so doing, we try to capture how this dictionary tackles this issue and how it suggests solutions.

Different studies on language and society have shown that language is political (Bourdieu 1992). That is, it ideologically privileges some points of view while downplaying others. From a systemic functional perspective, language being made up of various systems which in turn comprise various subsystems (Halliday 2004), the choice of a given system to the detriment of another or others is to be considered as always motivated. It is in this framework that the use of masculine phoric elements as epicenes has been decried for being genderbiased (Mills 1995). As an offshoot to this situation, several strategies have been suggested as a solution to this problem. To this end, the paper draws on OALD9 to address these various suggested strategies (i.e. expectations or rules) and match them with actual achievements (i.e. practice).

After a short discussion of the methodological issues, the paper will first explore gender-indexing phoric elements in English, pointing out when they may be gendered or ungendered. Second, it will address their treatment in 
OALD9 with a view to finding out whether or not there is a gap between the rules and actual practice in this respect. Finally, the paper will raise theoretical implications for the findings.

\section{Methodological considerations}

As regards data collection, this paper is basically a desk research (Sunderland 2006: xxiii) drawing on the skim-reading of OALD9 with a view to pointing out and describing gender-indexing phoric elements. That is, the lemmata selected are those belonging to the subclass of central pronouns which reflect the male-female natural gender contrast as well as their epicene counterparts (see section 3.1). In addition, some idiomatic expressions which include these phoric elements in either their definiendums or definiens are also selected to illustrate the dictionary's taking stance on structural gender-indexing in actual use.

As to the analysis of the data, the paper draws on lexical semantics (Van Roey 1990). Consideration will be taken of both the form (i.e. definiendum) and the meaning (i.e. definiens) of the lemma (i.e. phoric element) under study to point out whether it is gendered or ungendered. Furthermore, a selective choice will be made of Chomsky's Binding Theory (Cook 1988) in order to capture the reference relationships between antecedents and their phoric elements. Finally, the paper also draws on Critical Discourse Analysis (CDA) (Lazar 2005, Fairclough 2003) in order to show how the choice and treatment of a given phoric element may be ideologically loaded.

\section{On gender-indexing phoric elements}

The term gender-indexing phoric elements denotes gender-referring pronouns and adjectives which may function cataphorically or anaphorically (Halliday and Hasan 1976). Stated differently, they are those phoric elements likely to convey structural sexism or non-sexism, i.e. sexism or non-sexism which operates through syntagmatic relation within phrases, clause, sentences and/or text (Musau 1995, Mulamba and Tshimanga 2006, Tshimanga 2012, 2016, 2017a, 2017b and 2018). Such sexism is made explicit through the phrase structure or syntax, and particularly by considering coreferentiality between antecedents and their phoric elements (Cook 1988). Therefore, the linguistic context in which the gender-referring item is used becomes of paramount importance as it helps in deciding whether the item considered is gender-neutral or genderbiased. However, in the present study, the consideration of both the definiendum and the definiens of the phoric element will be of equal help.

Structural sexism is more inclusive than the sole consideration of phoric elements. For example, in her discussion of sexism at phrase and clause levels, Mills (1995) targets: (1) pre-constructed phrases, and (2) sentences, which, in turn includes proverbs, metaphors as well as jokes and humour. As already 
clarified earlier, in the framework of this situation, structural sexism will be restricted to the relationship of phoric elements and their antecedents. This being the case, the focus will be put on how gender is constructed through the central pronouns (Halliday and Hasan 1976) in both nominal and determiner functions (Quirk et al. 1985).

\subsection{Masculine pronouns as generic forms}

The term pronoun needs clarifying as it may be differently considered in terms of terminology and scope. From a terminological point of view, the term pronoun may be regarded as misnomer since it suggests that a pronoun deputizes for a noun in the structure. Instead, pronouns are surrogates to noun phrases whose case, number and gender-marking they reflect (Quirk et al. 1985). It is the latter characteristic, that is, gender-marking, which is of relevance to structural gender-indexing in English. In other words, not all pronouns are concerned with structural gender-indexing, but only those which actually express natural gender differentiation. In this regard, Quirk et al. (1985: 314) show that only '[s]ome 3rd person pronouns and wh-pronouns do ... express natural gender distinction.' The following instances illustrate this view.

(1) The boy $w_{i} w h o_{i}$ is outside the theatre has just wounded himself $f_{i}$.

(2) The girl who $_{i}$ is outside the theatre has just wounded herselfi .

The reflexive pronouns himself in (1) and herself in (2) respectively denote the masculine and the feminine, which corresponds to the male-female natural gender distinction. Besides, the relative pronoun who denotes the personal gender as contrasted with the nonpersonal one.

It is worth warning that wh-pronouns, although expressing the contrast personal vs. non-personal, are not to be considered for structural genderindexing on the ground that they do not show masculine vs. feminine distinction. Therefore, only the wider class of central pronouns is concerned by structural gender-indexing issues. In Quirk et al.'s (1985) understanding, these pronouns are called central pronouns because they share the features which are particularly characteristic of pronouns, viz. contrast of person, gender, and subjective/objective case. Furthermore, '[a]lthough these central pronouns fulfil different syntactic functions, they have obvious morphological resemblances.' The latter reason justifies the inclusion in the table below of the possessive her, for example - which is determinative in function and consequently cannot function alone as a surrogate to a noun (Quirk et al. 1985: 345-346). Halliday and Hasan (1976) use the term personal pronouns to refer to the traditional personal pronouns, possessive adjectives and pronouns, as well as reflexive pronouns; and justify this view with the centrality of these categories and their relevance to the descriptions of personal roles within discourse. Similarly, in their discussion of gender distinction in central pronouns in English, Quirk et 
al. (1985: 341) hold that '[g]ender distinctions are largely restricted to 3rd person singular pronouns of the categories of personal, possessive, and reflexive pronouns'. For the sake of inclusivity, the term gender-indexing phoric element will be used. The following table is an illustration.

Table 1: Gender-indexing phoric elements in English

\begin{tabular}{|l|l|c|c|c|c|c|}
\hline & Category & 1 & 2 & \multicolumn{2}{|c|}{3} & 4 \\
\hline \multirow{2}{*}{ Personal } & Masculine & he & him & \multicolumn{2}{|c|}{ his } & himself \\
\cline { 2 - 6 } & Feminine & she & her & her & hers & herself \\
\hline
\end{tabular}

(Adapted from Quirk et al. 1985: 341)

In the above table, the following categories of central phoric elements are clarified, (1) subjective, (2) objective, (3) possessive, and (4) reflexive. Besides, the above table shows that the subjective personal pronoun he, together with its objective, possessive, and reflexive counterparts, is explicitly masculine.

However, although grammarians, for example, Quirk et al. (1972 and 1985), Thomson and Martinet (1980), to mention but a few, define the pronoun he as masculine (i.e. as referring to men and male animals), they equally consider it as generic. That is, he is regarded as gender-indefinite or unmarked pronoun used to refer to both males and females simultaneously, as O'Grady et al. (1993: 434) demonstrate it: 'We do not employ he, for instance, to refer only to males. In Standard English, it is used as a generic third person singular pronoun when the sex of the referent is unknown or irrelevant'.

Such a use of phoric elements as generic is said to be gender-biased. Mills (1995: 87) defines generic forms as 'those elements in language which perpetuate a view of male as a norm or universal and the female as deviant or individual'. Generally speaking, such kind of sexism known as structural or grammatical sexism (Musau 1995; Mulamba and Tshimanga 2006) is made overt through a syntactic and/or semantic relation known as reference. This cohesive device includes, among other relations, exophora, also known as deixis (Neveu 2011: 111) or situational reference, and endophora or textual reference (Halliday and Hasan 1976) depending on whether it operates outside or within text. Endophora is further divided into anaphora (backward reference) and cataphora (forward reference) (Halliday and Hasan 1976).

The term anaphora denotes a within-discourse referential relation between two linguistic expressions, one of which known as anaphor or recall form, receives its interpretation of the referential sense of the other, called anaphor source or antecedent (Neveu 2011: 37). By contrast, the term cataphora denotes a withindiscourse referential relation between two linguistic expressions, one of which referentially dependent (i.e. cataphor or forward-pointing phoric element) receives in retroactive appearance its interpretation from another expression which is postposed to it (Neveu 2011: 72-3). The terms anaphora and cataphora 
are also respectively called 'unmarked-order anaphora' and 'marked-order anaphora' (Huddleston 1984) or 'syntactically-controlled anaphora' and 'pragmatically-controlled anaphora' (Hankamer and Sag 1976, cited in Huddleston 1984: 298).

In addition, Huang (2010:9) uses the terms anaphor and anaphoric as synonymous with anaphora and considers the latter to have three distinct senses in contemporary linguistics. In its first sense, this term 'can be used to refer to a relation between two or more linguistic elements, in which the interpretation of one element (called an anaphor or anaphoric expression) is in some way determined by the interpretation of another element (called an antecedent). And, the 'linguistic elements that can be employed to encode an anaphoric relation in this general sense range from phonetically unrealized gaps/zero anaphora/empty categories through pronouns and reflexives to various reference-tracking systems like gender/class, switch-function, and switch-reference'.

The second sense of the term is the one used by Chomsky's 'generative syntax for reference to a NP which has the features [+anaphor, -pronominal] versus pronominal as a NP with the features [-anaphor, +pronominal]'. In keeping with this view, Chomsky states three basic principles: A: An anaphor is bound in its domain; B: A pronominal is not bound in its domain, and C: An R-expression is free (see Cook 1988).

Finally, in the third sense, the term can be used to refer to an anaphoric expression whose antecedent comes earlier as opposed to 'cataphora/cataphor/ cataphoric', whereby the antecedent comes later. In fact, this latter sense is related to the first which is its superordinate. To avoid this confusion, use will be made of the term anaphora in Huang's (2010) sense (3) (i.e. anaphora vs. cataphora), and the term phoric element for the superordinate or as synonymous to anaphora in Huang's (2010) sense (1). Besides, Huang (2010: 9) shows that 'anaphora can be (intra-)sentential, in which case the anaphoric expression and its antecedent occur within a single simplex or complex sentence. It can also be discoursal, in which case the anaphoric expression and its antecedent cross sentence boundaries. In terms of syntactic category, Huang (2010: 9) distinguishes between (1) NP-anaphora and (2) VP-anaphora. Halliday and Hasan (1976) use the general term reference, which is wider in scope and subsumes endophoric vs. exophoric reference, but also personal, demonstrative and comparative reference.

Sexism is displayed in the first type of reference (i.e. personal reference) which is realized through the use of personal pronouns (i.e. the traditional personal pronouns, possessives and reflexives). Here, a masculine item denoting the 'other roles' i.e. third person singular, is used as coreferential with nouns of the personal dual class, the pronouns everyone, everybody, someone, somebody, one, together with their alternatives and possible combinations, to mention but these (Mulamba and Tshimanga 2006). Such a use of the pronoun he or its related forms as phoric (i.e. point back or forward) (Halliday and Hasan 1976) 
to dual nouns and pronouns which are not necessarily masculine is and has been considered as a case of prevailing sexism in the English language. For Mills (1995: 87), '[t]he generic "he" is perhaps the most well-known example of gender specific or sexist language, and is frequently referred to as "he-man" language'.

As Mills (1995: 88) observes, different researchers have shown that generic pronouns are often understood as referring to male. For example, students who were asked to complete fragmentary stories which contained the generic pronoun 'he', in most cases, completed the stories using 'he' as a sex-specific pronoun or a male named character. In addition, she paraphrases Robertson's research on visualization and generic pronouns which supports that people tend to visualize male participants when the supposed generic pronoun 'he' is used. Sometimes, sexism in the use of the generic he is implied by other non-verbal elements, such as images, which accompany the message. That is, although this phoric element may be used as gender-inclusive, its masculine-specific character will be revealed by the image accompanying it (Mills 1995: 88).

Furthermore, some people consider the use of the generic pronoun as confusing. This stems from the fact that, in a given context, such a pronoun can be interpreted as used generically or gender-specifically. Finally, also considered as sexist is the fact that gender-specific pronouns are used to refer to practitioners of some stereotypically male or female professions. Besides, when the sex of the person is not known, it is commonly assumed that the person is male (Mills 1995: 88). As can be noticed, such kind of gender-based bias is subtle as it is not explicitly made but implicated and is to be arrived at by drawing inferences from what is said.

\subsection{Suggested phoric element-degendering strategies}

To level sexism in the use of explicitly masculine phoric elements as epicene, various strategies have been suggested. According to Mills (1995), these include: (1) the use of plural pronouns, (2) the use of conjoined forms 's/he', '(s)he', 'he or she', 'she or he'; (3) passivization, (4) the use of the female pronoun as generic with a proviso , (5) the use of the male pronoun as generic with a proviso, (6) the use of alternate pronouns, and (7) the use of singular 'they' (see O'Grady et al. 1993; Quirk et al. 1985; Swan 1984). However, without providing any statistics related to the frequency of each of these alternate forms, Mills (1995: 97) notes that some people use 'she' for the first occurrence of the pronoun, and 'he' for the next, and so on; which has the disadvantage of being potentially confusing.

The use of plural pronouns implies pluralization of the whole clause while the use of the female pronoun as generic is based on a formal argument assuming that 'she' can be seen to contain 'he'. The use of alternate pronouns consists in using 'she' and 'he' in turn. That is, for example, 'she' is used for the 
first occurrence of the pronoun and 'he' for the next, and so on. The following instances illustrate:

(3) Each student $t_{i}$ submitted his $s_{i}$ assignment after he $e_{i}$ had completed it.

(4) All students submitted their $r_{i}$ assignments after they $y_{i}$ had completed it.

(5) Each student's assignment was submitted after it had been completed.

(6) Each student $t_{i}$ submitted his/her ${ }_{i}$ assignment after $s / h e_{i}$ had completed it.

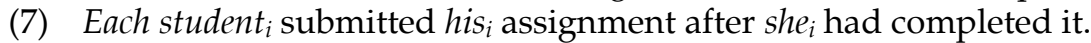

(8) Each student $t_{i}$ submitted her $r_{i}$ assignment after she $e_{i}$ had completed it.

(9) Each student ${ }_{i}$ submitted their ${ }_{i}$ assignment after they $y_{i}$ had completed it.

Instance (3) is the case of the use of the masculine as generic. Given that this is considered as gender-biased, its use has to be accompanied by a proviso. The latter is a note or a kind of disclaimer warning the reader that the use of he is intended as generic. As can be noticed, this should be done at the beginning of a book, for example, and especially in the introduction. Example (4) illustrates the use of plural phoric elements yielding the overall pluralization of the whole clause to neutralize gender-bias.

However, were the gender-inclusive term student replaced by a generic masculine one such as man, pluralization would be of little help. Instance (5) clarifies the use of passivization to level gender-bias. Actually, the aim here is to remove any phoric element which would reflect gender discrimination. Therefore, any rephrasing in this way may equally be welcome provided that it is not confusing. Example (6) is a case in point of the joint use of masculine and feminine phoric elements while (7) illustrates the alternate use of the masculine and feminine as coreferential with the same antecedent. This strategy seems confusing insofar as the phoric elements may be interpreted as coreferential to different antecedents. Instance (8) is all about the use of the feminine phoric element as gender-inclusive while (9) illustrates the use of plural they.

Each of the above strategies has its specificity of use. For example, the use of the masculine phoric element as generic with a proviso is more likely to occur in the written rather than in the spoken medium. Similarly, while the singular they might occur in both media, it is generally regarded as occurring in the informal style. Accordingly, commenting on the latter case, Swan (1984: 236) writes that '[a]nybody, anyone, somebody, someone, nobody, no-one, everybody and everyone are used with singular verbs ... we often use they, them and their to refer to these words, especially in an informal style'. Admittedly, usage has evolved since as shown in other posterior studies below. For example, drawing on The Comprehensive Grammar of the English Language, Sunderland (2006: 12) sustains that the singular they is 'now increasingly accepted even in formal usage'. To put it clearly, the singular they is used as coreferential to either an indefinite pronoun or a noun phrase whose head is a dual noun. However, wherever there is a gender-specific item, use is made of either he or she exclusively (O'Grady et al. 1993: 434). 
Similar to the above use is the case in which the indefinite one occurs as antecedent. Gender-bias can be avoided, here, by repeating one as phoric to one in every configuration, for example 'One should never criticize if one is not sure of one's facts'. This is actually the use of the indefinite one which denotes 'people in general' or 'I' when the speaker is referring to himself or herself. Such a 'use of one is very formal and now sounds old-fashioned'. Thus, the pronouns you and $I$ are currently much more usual for the first and the second meaning respectively (Hornby 2015: 1076). However, the joint use of the masculine and the feminine or the use of the singular they would be equally acceptable.

Furthermore, the zest to wipe out sexism based on generic he has led some researchers to coin "unisex pronouns" SE (he/she), SEM (him/her), SES (his/her/ hers), and SEMSELF (himself/herself) (Abdel-Nabi and Hilfi 1989, Musau 1995). Full capitalization of these forms may be intended for highlight. Actually, such an attempt is one of the response strategies to the problem generated by the absence of a true sex-neutral 3rd person singular pronoun in English (Herbert and Nykiel-Herbert 1986: 52). Accordingly, they argue 'Specific proposals for new pronouns abound, e.g. co, tey, hesh, thon, xe, E, po.' Such a coinage might have been carried out on the basis of some diachronic or synchronic linguistic justification. For example, Miller and Swift (1977) (cited by Herbert and NykielHerbert 1986: 52) argue that 'such coinages are not new: thon, for example derives from that one and was first recorded in 1859 and has been listed in many standard reference works'.

Table 2 below recapitulates on different proposals (i.e. expectations) regarding the use of gender-inclusive pronouns or epicenes, as well as their masculine and feminine counterparts.

Table 2: Gender-indexing phoric elements with suggested revisions

\begin{tabular}{|c|c|c|c|c|c|c|c|}
\hline & & & \multicolumn{2}{|l|}{ Personal } & \multicolumn{2}{|l|}{ Possessive } & \multirow[t]{2}{*}{ Reflexive } \\
\hline & & & Subjective & Objective & Determinative & Independent & \\
\hline \multirow{6}{*}{ Personal } & Masculine & 1 & he & him & \multicolumn{2}{|c|}{ his } & himself \\
\hline & Feminine & 2 & she & her & her & hers & herself \\
\hline & \multirow{4}{*}{ Epicene } & 3 & (s)he, s/he & him/her & his/her & his/hers & him-/herself \\
\hline & & 4 & they & them & their & theirs & themselves \\
\hline & & 5 & $S E$ & SEM & \multicolumn{2}{|c|}{ SES } & SEMSELF \\
\hline & & 6 & \multicolumn{5}{|c|}{ co, tey, hesh, thon, xe, E, po } \\
\hline \multicolumn{2}{|c|}{ Nonpersonal } & & \multicolumn{2}{|c|}{ it } & its & & itself \\
\hline
\end{tabular}

The above table needs commenting for clarification. Pronouns in (1) are explicitly masculine and illustrate the proposal according to which the masculine may be used as generic with a proviso. Although explicitly feminine, (2) illustrates the 
proposal supporting the use of the feminine as generic while (3) illustrates the joint use of the masculine and feminine as epicene. Option (4) illustrates the use of the singular they while options (5) and (6) are all about completely invented forms, without current relevance to everyday language use. While forms in (1) to (4) are actually used in everyday discourse, those in (5) and (6) are still but mere suggestions. Forms in (1) to (5) have a complete distribution across different types of central pronouns: personal, possessive, and reflexive. Although the table also outlines nonpersonal phoric elements for a complete picture of the situation, it leaves out two of strategies described above consisting, in turn, (1) in repeating indefinite one and in (2) alternatively using the masculine and feminine in the same text. This is justified by two facts: (1) the impossibility to tabulate the latter strategy and (2) the irrelevance of the indefinite one to the issue of indicating the speech roles (see Halliday and Hasan 1976).

By way of a conclusion, it is worth noting that the discussion of degendering strategies in this section is intended to serve illustrative purpose. This stems from the fact that the scope of sexism is so wide that it cannot be restricted to word or sentence level. That is, it can be conveyed in rather subtle ways at discourse level and involving, for example, talk in interaction where it may be deployed through a wide range of other strategies. On the other hand, designing strategies for the degendering of the English language is not the whole story. Rather, it is just a step on the scale of gender-neutral language implementation; and the latter is not without its problems, as will be clarified below.

\subsection{Treatment of gender-indexing phoric elements in OALD9}

Since structural or grammatical gender-indexing is made possible through the cohesive relation of reference, it is important to discuss in turn different phoric elements which enter this relationship. Such phoric elements are those belonging to the category of central pronouns, and which explicitly refer to genderreferring antecedents. These gender-indexing phoric elements are discussed in the following examples.

\section{Definiendum $\quad$ Definiens}

(10) $\mathrm{He}$

(11) She
Pron. (used as the subject of a verb) (1) a male person or animal that has already been mentioned or is easily identified....

(2) (becoming old-fashioned) a person, male or female, whose sex is not stated or known, especially when referring to sb mentioned earlier or to a group in general: Every child needs to know that he is loved. (saying) He who (=anyone who) hesitates is lost $\rightarrow$ NOTE AT GENDER (OALD9: 723)

(used as the subject of a verb) a female person or animal that has already been mentioned or is easily identified: 'What does your sister do?' 'She's a dentist.' $\rightarrow$ NOTE AT GENDER

(OALD9: 1425) 

be either female (she) or male (he): If a student does not attend all the classes, s/he will not be allowed to take the exam. (OALD9: 1425) person whose sex is not mentioned or not known: Does anyone here consider themself a good cook? HELP: Although themself is fairly common, especially in spoken English, many people think it is not correct. (OALD9: 1622)

(14) They

Used instead of he or she to refer to a person whose sex is not mentioned or not known: If anyone arrives late they'll have to wait outside. $\rightarrow$ NOTE AT GENDER (OALD9: 1625)

Example (10) reveals that, although becoming old-fashioned, the subjective masculine pronoun he is considered as generic, that is, as also referring to both masculine and feminine antecedents. This would lead to the interpretation that the dictionary still, somehow, perpetuates some fossils of biased usage as far as gender representation in phoric elements is concerned. However, the presence of the diachronic label becoming old-fashioned might be considered as a strategy aimed at discouraging the user in the choice of this phoric element.

By contrast, its feminine counterpart, i.e. the subjective pronoun she in (11) is considered as specific. This shows that its generic meaning commonly found in feminists' writers has been simply omitted. This omission might also be regarded as contribution to the obfuscation of femininity. The form s/he in (12) is used in writing to refer to gender-inclusive antecedents. In fact, we are of the view that the feminine generic meaning could at least be signalled, although with some usage comments.

Besides, in (13) the reflexive pronoun themself is a recent coinage regarded as a gender-neutral phoric form coreferential with a gender-inclusive indefinite pronoun or a noun phrase whose head is a dual noun. On the other hand, the use of the phoric element themself as epicene has not yet reached general consensus. That is the reason why it is followed by a usage note which warns the user that it is still a case of divided usage.

Finally, (14) is the case of singular they used as coreferential with a dual antecedent. Once again, this entry is accompanied with a cross-reference leading the user to discover more information on the item considered.

Gender-indexing through phoric elements in OALD9 can be presented in tabular form as below. 
Table 3: Gender-indexing phoric elements in OALD9

\begin{tabular}{|c|c|c|c|c|c|c|c|}
\hline & & & \multicolumn{2}{|l|}{ Personal } & \multicolumn{2}{|l|}{ Possessive } & \multirow[b]{2}{*}{ Reflexive } \\
\hline & & & Subjective & Objective & Determinative & Independent & \\
\hline \multirow{3}{*}{ Personal } & Masculine & 1 & he & him & \multicolumn{2}{|c|}{ his } & himself \\
\hline & Feminine & 2 & she & her & her & hers & herself \\
\hline & Epicene & 3 & s/he, they & them & their & theirs & themself(ves) \\
\hline \multicolumn{2}{|c|}{ Nonpersonal } & 4 & \multicolumn{2}{|c|}{ it } & its & & itself \\
\hline
\end{tabular}

This table shows both personal gender-indexing in (1) to (3), and nonpersonal gender-indexing in (4), with only the former being considered relevant to the issues of sexist and non-sexist gender-encoding. The inclusion of both personal and nonpersonal gender-indexing is intended to provide a thorough picture of gender differentiation in the central pronouns. The phoric element he - together with its different related objective, possessive or reflexive forms - in (1) stands for both specific masculine reference, which is its canonical use, and gender-inclusive reference, that is, gender-indexing subsuming both male and female. In addition, the phoric element she - including its related forms - in (2) illustrates feminine reference.

It is worth pointing out, by the same token, that the gender-inclusive meaning of she is spoken about in the more-about-gender usage note, but is not lexicalized in OALD9. Finally, s/he and they in (3) - as well as their related forms - illustrate coreferentiality with gender-inclusive antecedents. Note also that other proposals for conjoining the masculine and the feminine - such as (s)he, he/she, he or she, his/her, his or her, etc. - are not lexicalized in OALD9, although they are discussed in the more-about-gender usage note.

\subsection{Gender construction through gender-indexing phoric elements}

\subsubsection{Lexicalization of gender-indexing phoric element}

As to gender construction through phoric elements, the analyses have revealed that OALD9 keeps perpetuating the use of generic he. Conversely, it makes use of the joint form $s / h e$, the singular they, and the gender-inclusive reflexive phoric form themself, all of which are explicitly lexicalized in the dictionary. Apart from these, the generic feminine she, and the joint forms (s)he, his/her, he or her are made mention of in the more-about-gender usage note but are not lexicalized in the word list. Table 4 summarizes lexicalization and lexical gapping of gender-referring phoric elements in OALD9. 
Table 4: Lexicalization of gender-indexing phoric elements

\begin{tabular}{lllc}
\hline $\mathrm{N}^{0}$ & Phoric form & Description & OALD9 \\
\hline 1 & $\mathrm{He}$ & Masculine & + \\
\hline 2 & $\mathrm{He}$ & Generic & + \\
\hline 3 & She & Feminine & + \\
\hline 4 & She & Generic & $(+)$ \\
\hline 5 & $($ S)he & Generic & $(+)$ \\
\hline 6 & S/he & Generic & - \\
\hline 7 & They & Singular & - \\
\hline 8 & Themself & Singular & + \\
\hline
\end{tabular}

This table presents different phoric forms as well as their occurrences in OALD9. The plus sign (+) means that the item is lexicalized in the dictionary while the minus sign (-) means that the item does not occur. By contrast, the plus sign enclosed in parentheses $((+))$ means that the item is only mentioned but not lexicalized in the word list. Similarly, it is important to note that, apart from themself which is a reflexive pronoun; the others are subjective personal pronouns and are intended as canonical forms. As such, they stand for other related forms of the central pronoun subclass. Finally, the subjective personal pronouns (s)he in (5) and s/he in (6) are cases of blending.

These blends offer an insight from the theoretical matter stand and from that of gender-based ideology. From the theoretical point of view, they reveal two new tendencies of spelling blends which we call 'parenthetical blend' as in (s)he and 'slashed or slanted blend' as in s/he. These add up to the commonest typologies of 'solid blend' as in brunch from breakfast + lunch, and 'hyphenated blend' as in wi-fi (from wireless fidelity). However, cases of 'open blends' on the pattern of 'open compound' are still to find. In s/he or (s)he, the slash and the parentheses are inserted for ideological purposes. That is, they filter the overlap between the use of feminine she as generic and these new coinages, intended to be sex-inclusive. Were the slash and parentheses deleted, the debates of using a given specific form as generic would result and reduce its chance of consensual acceptability.

Note that this terminology is coined after that of compounds subsuming solid compounds as in classroom where the two components are tied up together, open compounds such as food box where the two component parts are separated from each other by a space, and hyphenated compounds as in shortsighted whose elements are conjoined by a hyphen. From the perspective of gender ideology, the use of a slant or slash $(/)$ in $s / h e$ and that of parentheses in 
(s)he is ideological as it is intended to preclude the spelling of the blend as she, which would be a case of reversing the marking.

Interestingly, this tendency does occur in some writing, most of which by feminist writers. Furthermore, from a theoretical perspective, it can be argued that these blends have introduced a new role of the slant or slash as well as that of parentheses, which is of playing the role of conjoining parts of a blend. This role is coterminous with that of the hyphen. Next, would one dig up the usual meaning associated with these writing mechanics, that is separating alternatives constituent for the slash or stroke and enclosing optional information for the parentheses (Quirk et al. 1985), this would send us back to square one.

To conclude, Table 4 above has important implications for the understanding of the central pronouns functioning as gender-inclusive phoric elements. Therefore, the current state of these phoric elements may be presented as in Table 5 below.

Table 5: Degendering phoric elements: Current state of the art

\begin{tabular}{|c|c|c|c|c|c|c|c|}
\hline \multirow{9}{*}{ 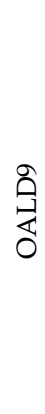 } & \multirow{7}{*}{ 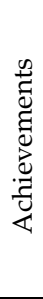 } & & \multicolumn{2}{|l|}{ Personal } & \multicolumn{2}{|l|}{ Possessive } & \multirow[t]{2}{*}{ Reflexive } \\
\hline & & & Subjective & Objective & Determinative & Independent & \\
\hline & & 1 & *he & him & \multicolumn{2}{|c|}{ his } & himself \\
\hline & & \\
\hline & & 2 & ${ }^{*}$ she & her & her & hers & herself \\
\hline & & 3 & (s)he, s/he & him/her & his/her & his/hers & him-/herself, themself \\
\hline & & 4 & they & them & their & theirs & themselves \\
\hline & \multirow{2}{*}{$\underset{0}{\infty}$} & 5 & $S E$ & SEM & \multicolumn{2}{|c|}{ SES } & SEMSELF \\
\hline & & 6 & \multicolumn{5}{|c|}{ co, tey, hesh, thon, xe, E, po } \\
\hline
\end{tabular}

This table presents the current configuration of the central pronouns actually used and/or simply proposed in the degendering of the English language. It comprises three different strata. The first, which coincides with the view still perpetuated in OALD9, is represented by option (1) in the table. That is, it is all about the use of the masculine phoric element as generic. Two options may be noted. First, if native speakers have actually stopped using the generic he, and OALD9 still somehow maintain it, it may be said to be norm-prescriptive in maintaining or perpetuating the status quo. The other side of the coin is that this dictionary might be said norm-descriptive in reflecting actual usage. This may transpire through a careful consideration of the sentence Every child needs to know that he is loved (OALD9: 723), which has been taken from naturally occurring evidence. The second stratum comprises options (2) to (4) which are specific to OALD9. Option (2) is all about the reversal of the marking or the use of the feminine as generic. This option is likely to raise contention associated with option (1); that is why both of them are starred. 
Since OALD9 simply describes option (2), it is said to be norm-descriptive in this regard. Options (3) and (4) are about the joint use of masculine and feminine phoric elements and the use of the singular they. In option (3) the blend s/he is lexicalized while (s)he is simply mentioned. It is also important to note the emergence of the gender-inclusive reflexive phoric element themself in the same option. Finally, the third stratum constitutes lexical gaps or forms not yet attested. It is made up of option (5) which has the subjective as well as its objective, possessive, and reflexive counterparts; and option (6) whose elements are cross-functional. These gaps would be justified by their absence from the corpus since they are artificially coined and not actual specimens of language in use.

\subsubsection{Dictionary use and exclusion of gender-indexing phoric elements}

The earlier discussion was devoted to lexicalization or gapping of genderindexing phoric elements as well as their treatment in OALD9. This subsection attempts to address actual examples of use of gender-indexing phoric elements in order to point out which ones of such forms are actually used in this dictionary. This would reveal which stance the dictionary takes in this regard. To achieve this task, some idiomatic expressions were randomly selected as illustrations given the presence of a gender-referring phoric element in their structure. Consideration will be made of both their definiendums and the definiens.

Definiendum

(15) Every man for himself

(16) $\underline{\text { He }}$ who laughs last laughs longest

\section{Definiens}

(saying) People must take care of themselves and not give or expect any help (OALD9: 945)

(saying) used to tell $s \boldsymbol{b}$ not to be too proud of their present success; in the end another person may be more successful (OALD9: 880)

To leave sb alone to do as they wish, and not tell them what to do (OALD9: 420)

to give $\underline{s}$ /sth a number of tasks to perform in order to see what they are capable of doing (OALD9: 1105)

Walk $\underline{\boldsymbol{b}}$ off their feet (informal) to make $\underline{\boldsymbol{s}} \boldsymbol{b}$ walk so far or so fast that they are very tired (OALD9: 1751)

Regarding actual use of gender-indexing phoric elements in the definiendum, it can be argued that only the generic masculine, examples (15) and (16), and the singular they, examples (17) to (19), are attested. By contrast, in the definiens, gen- 
eralized pluralization, examples (15), and the singular they, examples (16) to (19) are actually used. However, it is worth noting that the gender-indexing phoric forms in the definiendums were probably taken as such from a corpus as naturally occurring specimens rather than lexicographer-intentionally selected. Conversely, those in the definiens may be considered the other way around as they are part of the lexicographers' choice of the defining vocabulary. The forthcoming section summarizes and concludes the overall discussion.

\section{Conclusion}

This paper was based on the premise that non-sexism is one of obvious proofs of the interaction between social and cultural changes in the English speech community. Therefore, for illustrative purposes, it drew on OALD9 in order to address the degendering of phoric elements and the related efforts to capture and express social and cultural changes in the English language. It has been found out that OALD9 draws on the potential provided by the English language in order to put forward a variety of degendering strategies, to the exclusion of those artificially proposed by various scholars.

On this ground, OALD9 is to be regarded as an invaluable tool for nonnative speakers insofar as it draws their attention to and raises their awareness of the issues which are often left unaddressed in common (elementary) grammar books. However, it is important to add that this dictionary does not propose a monolithic solution to the degendering of phoric elements, nor does it take into account all the proposed degendering strategies. For example, the use of feminine as generic is not even mentioned. Besides, despite the coinage of epicene forms, the generic masculine phoric elements still appear. Although this state of affairs may show that the dictionary aims at being neutral in just describing language in use, it also reveals that it takes a stance in privileging some strategies to the detriment of others. For instance, in the defining vocabulary, the use of generalized pluralization and the singular they are intentionally favoured by the lexicographers.

This situation has three main insightful theoretical consequences. First, there is still a real gap between rules and actual practice. Second, non-sexism is still a usage problem insofar as all the language users do not agree about the rules. Even native speakers have to learn these new conventions - a violation of the psycholinguistic saying according to which language is what a native speaker says it is. Finally, the use of more than one structure to achieve nonsexism is seen as making fluency difficult and writing cumbersome. 


\section{References}

Abdel-Naby, M. and H. Hilfi. 1989. Introducing the Unisex Pronoun. English Teaching Forum 27(3): 42-43. Bourdieu, P. 1992. Language and Symbolic Power. Cambridge: Polity Press.

Cook, V.J. 1988. Chomsky's Universal Grammar: An Introduction. Oxford: Basil Blackwell.

Fairclough, N. 2003. Analysing Discourse: Textual Analysis for Social Research. New York: Routledge.

Halliday, M. 2004. An Introduction to Functional Grammar. London: Routledge.

Halliday, M.A.K. and R. Hasan. 1976. Cohesion in English. London: Longman.

Hankamer, J. and I. Sag. 1976. Deep and Surface Anaphora. Linguistic Inquiry 7(3) 391-426.

Herbert, R.K. and B. Nykiel-Herbert. 1986. Explorations in Linguistic Sexism: A Contrastive Sketch. Available at: http://wa.amu.edu.pl/psicl/files/21/05Herbert\&Nykiel-Herbert.pdf.

Hornby, A.S. 2015. Oxford Advanced Learner's Dictionary of Current English. Ninth Edition. Oxford: Oxford University Press.

Huang, Y. 2010. Pragmatics of Anaphora. Cummings, L. (Ed.). 2010. The Routledge Pragmatics Encyclopedia: 9-13. London/New York: Routledge.

Huddleston, R. 1984. Introduction to the Grammar of English. Cambridge/New York: Cambridge University Press.

Lazar, M.M. (Ed.). 2005. Feminist Critical Discourse Analysis: Gender Power and Ideology in Discourse. New York: Palgrave MacMillan.

Miller, C. and K. Swift. 1977. Words and Women: New Language in New Times. Garden City, NY: Anchor Press/Doubleday.

Mills, S. 1995. Feminist Stylistics. London: Routledge.

Mulamba, N.G. and N. Tshimanga. 2006. Non-sexism as a Usage Problem in English. Annales de l'I.S.P.-Mbujimayi 14: 133-152. Mbujimayi: CANDIP-I.S.P.

Musau, G.M. 1995. Sexism and Africanisms. English for Africa Series (Book Three and Book Four). Licence Dissertation. Mbujimayi: I.S.P., English Department.

Neveu, F. 2011. Dictionnaire des sciences du langage. Second revised and expanded edition. Paris: Armand-Colin.

O'Grady, W., M. Dobrovolsky and M. Aronoff. 1993. Contemporary Linguistics: An Introduction. Second Edition. New York: St. Martin's Press.

Quirk, R., S. Greenbaum, G. Leech and J. Svartvik. 1972. A Grammar of Contemporary English. London: Longman.

Quirk, R., S. Greenbaum, G. Leech and J. Svartvik. 1985. A Comprehensive Grammar of the English Language. London: Longman.

Sunderland, J. (Ed.) 2006. Language and Gender: An Advanced Resource Book. London: Routledge.

Thomson, A.J. and A.V. Martinet. 1980. A Practical English Grammar. Third Edition. Oxford: O.U.P.

Tshimanga, F.N.C. 2012. Sexisme dans les Anglicismes. LITERA 25(2): 1-31.

Tshimanga, F.N.C. 2016. Gender Bias in Bantu Languages: The Case of Cilubà (L31). Abbou, J. and F.H. Baider (Eds.). 2016. Gender, Language and the Periphery: Grammatical and Social Gender from the Margins: 129-164. Amsterdam: John Benjamins.

Tshimanga, F.N.C. 2017a. Degendering the English Language: Achievements and Gaps, The Case of Oxford Advanced Learner's Dictionary. Third Edition. Unpublished M.A. Dissertation. Kinshasa: University of Kinshasa, Faculty of Arts — Department of English Letters and Civilization. 
http://lexikos.journals.ac.za; https://doi.org/10.5788/30-1-1589

292

Nshindi-Germain Mulamba and Francis Ngoyi Crequi Tshimanga

Tshimanga, F.N.C. 2017b. Lexical Gender-Indexing, Sexism, and Non-Sexism in The Oxford Advanced Learner's Dictionary. Third Edition. Annales de la Faculté des Lettres et Sciences Humaines, Université de Kinshasa. Vol. 18: 67-91.

Tshimanga, F.N.C. 2018. Gender-indexing Phoric Elements in Idioms: Peeping into Oxford Advanced Learner's Dictionary. Third Edition. Journal of Advanced Linguistic Studies 7(1-2): 121-144..

Van Roey, J. 1990. French-English Contrastive Lexicology: An Introduction. Louvain-La-Neuve: Peeters. 